\title{
Providers' attitudes and practices regarding emergency contraception in India: Key findings
}

\author{
M.E. Khan \\ Population Council \\ Isha Bhatnagar \\ Population Council \\ Deepthi S. Varma \\ Population Council \\ Anvita Dixit \\ Population Council
}

\begin{abstract}
Follow this and additional works at: https://knowledgecommons.popcouncil.org/departments_sbsr-rh
Part of the Health Policy Commons, International Public Health Commons, Obstetrics and Gynecology Commons, Pharmacy and Pharmaceutical Sciences Commons, Public Health Education and Promotion Commons, and the Women's Health Commons How does access to this work benefit you? Let us know!
\end{abstract}

\section{Recommended Citation}

Khan, M.E., Isha Bhatnagar, Deepthi S. Varma, and Anvita Dixit. 2012. "Providers' attitudes and practices regarding emergency contraception in India: Key findings," program brief. New York: Population Council. 


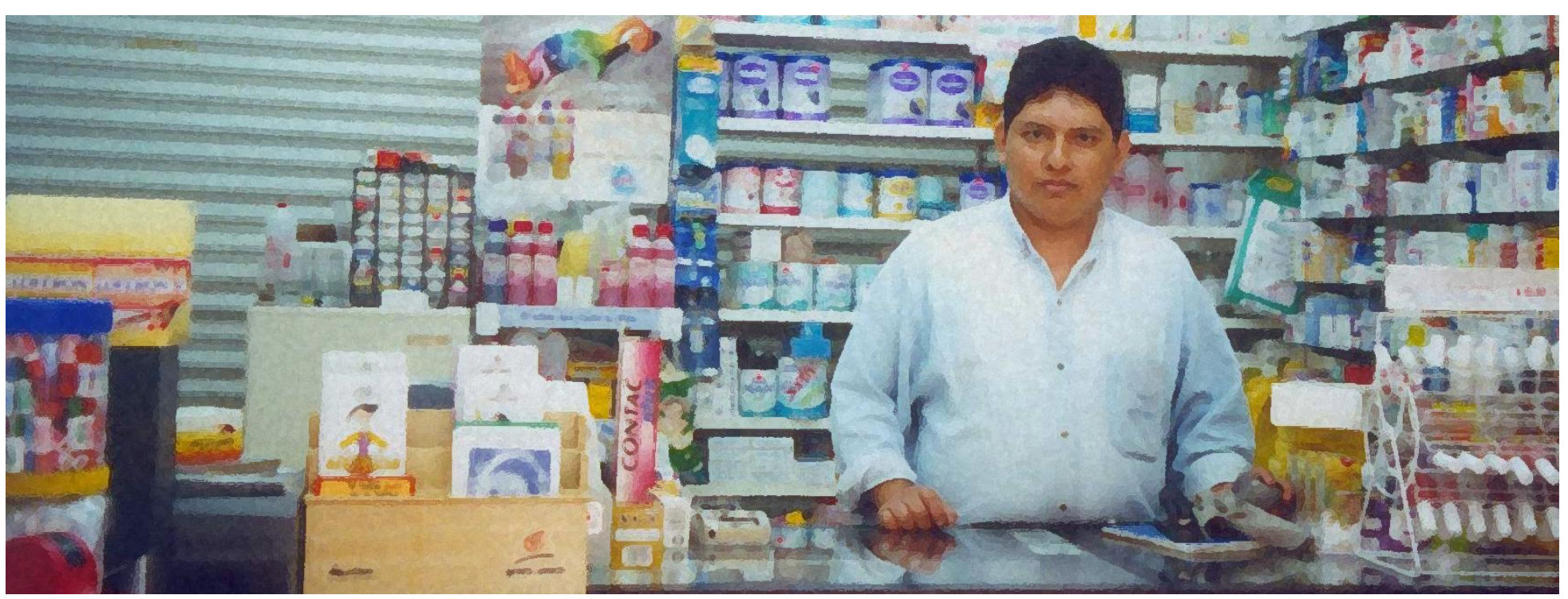

\section{BACKGROUND}

The emergency contraceptive pill (ECP) is an effective postcoital contraceptive method, providing women with the opportunity to avoid unwanted pregnancy after sex in which a contraceptive either was not used or failed. In India, where unintended pregnancy rates are high, ECP was included in the National Family Planning Program in 2002 and made an over-the-counter (OTC) drug in 2005. Since ECP has been made available OTC, concerns have been raised that the easy availability and lack of knowledge regarding correct use of ECP-even among providers-may lead to its misuse, its repeat use within the same menstrual cycle, replacement of precoital family planning methods, and an increase in promiscuity. Although no serious harmful effects have been associated with repeat use of ECP, the method should not be used repeatedly because it is less reliable than other modern methods of birth spacing.

\section{OBJECTIVE}

The present study explores providers' knowledge of how ECP works and its safety and effectiveness, their perceptions of the frequency of repeat use, their provision of ECP, and their attitudes toward women who seek it.

\section{METHODOLOGY}

A quantitative survey of 315 providers-199 pharmacists, $83 \mathrm{OB} / \mathrm{GYN}$ doctors, 33 paramedics-was conducted in four cities of Uttar Pradesh (Agra, Aligarh, Kanpur, and Lucknow) and in Delhi. The sampling frame for Uttar Pradesh was drawn from a list of doctors and pharmacies provided by the Urban Health Initiative. The sampling frame for Delhi was limited to pharmacies and was created by dividing the city into four sections and randomly sampling pharmacies from each section. (A qualitative study of 19 key opinion leaders was also conducted, and those findings are presented elsewhere.)

\section{FINDINGS}

- Most of the doctors (96 percent) knew the mechanism by which ECP prevents pregnancy. In contrast, 40 percent of paramedics and 61 percent of pharmacists lacked such knowledge.

- Eighty-six percent of providers believed that ECP is safe, and 82 percent thought it was very effective in preventing pregnancy.

- Forty-three percent of doctors, 24 percent of paramedics, and only 11 percent of pharmacists had ever received training in ECP. 
Very few (13 percent) had received literature on ECP, provided mainly by pharmaceutical firms.

- Ninety percent of doctors, 72 percent of paramedics, and 55 percent of pharmacists knew that ECP cannot induce abortion.

- Many doctors and paramedics mistakenly believed that ECP cannot be used by women with heart problems or who are breastfeeding.

- Doctors expressed greater reservations than did other providers about ECP use, distribution as an OTC drug, and provision by paramedics.

- Male providers were more than three times as likely as female providers $(\mathrm{OR}=3.5, \mathrm{p}<0.01)$ to support availability of ECP as an OTC drug.

- Logistic regression analysis showed that providers who are male, young (aged 15-35 years), and trained were two times as likely to support ECP provision, compared with their female, older (35+), and untrained counterparts, respectively.

- The majority of providers (72 percent of pharmacists, 57 percent doctors) believed that many women are using ECP repeatedly, but not necessarily in the same cycle.

TABLE 1 Percentage of providers expressing various attitudes toward ECP $(\mathrm{N}=315)$

\begin{tabular}{lccc}
\hline Attitude & $\begin{array}{l}\text { Doctors } \\
(\mathbf{n = 8 3})\end{array}$ & $\begin{array}{l}\text { Paramedics } \\
(\mathbf{n}=\mathbf{3 3})\end{array}$ & $\begin{array}{l}\text { Pharmacists } \\
(\mathbf{n}=\mathbf{1 9 9})\end{array}$ \\
\hline $\begin{array}{l}\text { Disapproved of OTC } \\
\text { availability of ECP }\end{array}$ & 67 & 61 & 34 \\
$\begin{array}{l}\text { Believed ECP use } \\
\text { among unmarried girls } \\
\text { is appropriate }\end{array}$ & 29 & 33 & 49 \\
$\begin{array}{l}\text { Favored minimum-age } \\
\text { restriction for ECP use }\end{array}$ & 84 & 94 & 74 \\
$\begin{array}{l}\text { Believed ECP use will } \\
\text { promote promiscuity }\end{array}$ & 45 & 59 & 46 \\
$\begin{array}{l}\text { Believed people may } \\
\text { use ECP as regular } \\
\text { contraceptive }\end{array}$ & 39 & 30 & 31 \\
$\begin{array}{l}\text { Approved provision of } \\
\text { ECP as prophylactic }\end{array}$ & 48 & 58 & 58 \\
\hline
\end{tabular}

\section{POLICY IMPLICATIONS}

Many of the findings of this study are encouraging. Most providers believed that ECP is an effective and safe method to prevent pregnancy and that it cannot induce abortion, and half supported the OTC provision of ECP. Although most providers (88-92 percent) viewed married women as the most appropriate users of ECP, 42 percent approved its use among unmarried girls. Nevertheless, the study revealed many biases and gaps in knowledge. The majority of doctors oppose OTC availability of ECP and its provision by those lacking medical training. Few providers reported receiving any orientation or literature regarding ECP. The study also found that in urban areas, particularly large cities like Delhi, ECP use is common, and that many users are young and unmarried. Repeated use of ECP is confirmed by pharmacists who have returning customers. These findings suggest that the following steps should be taken:

1. An educational campaign is needed to overcome the negative attitudes toward ECP among doctors and other stakeholders.

2. Advertisements for condoms and the pill should mention ECP as a backup method.

3. Companies that advertise their ECP brand on TV and in newspapers should state clearly that ECP is not intended for use as a primary contraceptive method. Similarly, ECP packaging should state that it is only for emergency use.

4. Medical representatives, wholesalers, and pharmacists' associations should educate pharmacists about the correct use of ECP and, when possible, provide a brochure explaining how ECP works and its correct use.

5. A formative study should be undertaken to assess the feasibility of using pharmacies-the main direct supply point for ECP-as a source of information for ECP users.

The Population Council confronts critical health and development issues-from stopping the spread of HIV to improving reproductive health and ensuring that young people lead full and productive lives. Through biomedical, social science and public health research in about 50 countries, the Council works with our partners to deliver solutions that lead to more effective policies, programs, and technologies to improve lives worldwide. Established in 1952 and headquartered in New York, the Council is a nongovernmental, nonprofit organization with an international board of trustees.

www.popcouncil.org

(c) 2012 The Population Council, Inc.
Population Council, Zone 5A, Ground Floor India Habitat Centre, Lodi Road, New Delhi - 110003 